\title{
Economic evaluation of treatments for patients with localized prostate cancer in Europe: a systematic review
}

Virginia Becerra 1,2, Mónica Ávila, 1,2,3, Jorge Jimenez ${ }^{1}$, Laura Cortes-Sanabria 1,4, Yolanda Pardo 1,3, Olatz Garin 1,2,3, Angels Pont ${ }^{1,3}$, Jordi Alonso ${ }^{1,2,3}$, Francesc Cots ${ }^{5,6}$, Montse Ferrer ${ }^{1,2,7^{*}}$ (D) and on behalf of the Multicentric Spanish Group of Clinically Localized Prostate Cancer

\begin{abstract}
Background: Our objective was to assess the efficiency of treatments in patients with localized prostate cancer, by synthesizing available evidence from European economic evaluations through systematic review.

Methods: Articles published 2000-2015 were searched in MEDLINE, EMBASE and NHS EED (Prospero protocol CRD42015022063). Two authors independently selected studies for inclusion and extracted the data. A third reviewer resolved discrepancies. We included European economic evaluations or cost comparison studies, of any modality of surgery or radiotherapy treatments, regardless the comparator/s. Drummond's Checklist was used for quality assessment.
\end{abstract}

Results: After reviewing 8,789 titles, 13 European eligible studies were included: eight cost-utility, two costeffectiveness, one cost-minimization, and two cost-comparison analyses. Of them, five compared interventions with expectant management, four contrasted robotic with non robotic-assisted surgery, three assessed new modalities of radiotherapy, and three compared radical prostatectomy with brachytherapy. All but two studies scored $\geq 8$ in the quality checklist. Considering scenario and comparator, three interventions were qualified as dominant strategies (active surveillance, robotic-assisted surgery and IMRT), and six were cost-effective (radical prostatectomy, roboticassisted surgery, IMRT, proton therapy, brachytherapy, and 3DCRT). However, QALY gains in most of them were small. For interventions considered as dominant strategies, QALY gain was 0.013 for active surveillance over radical prostatectomy; and 0.007 for robotic-assisted over non-robotic techniques. The highest QALY gains were 0.57-0.86 for radical prostatectomy vs watchful waiting, and 0.72 for brachytherapy vs conventional radiotherapy.

Conclusions: Currently, relevant treatment alternatives for localized prostate cancer are scarcely evaluated in Europe. Very limited available evidence supports the cost-effectiveness of radical prostatectomy over watchful waiting, brachytherapy over radical prostatectomy, and new treatment modalities over traditional procedures. Relevant disparities were detected among studies, mainly based on effectiveness. These apparently contradictory results may be reflecting the difficulty of interpreting small differences between treatments regarding QALY gains.

Keywords: Cost-effectiveness analysis, Cost-utility analysis, Cost-benefit analysis, Prostatic neoplasms, QALY, Qualityadjusted life years

\footnotetext{
* Correspondence: mferrer@imim.es

${ }^{1}$ Health Services Research Group, IMIM (Hospital del Mar Medical Research Institute), Barcelona, Spain

${ }^{2}$ Universitat Pompeu Fabra, Barcelona, Spain

Full list of author information is available at the end of the article
} 


\section{Background}

Prostate cancer is the second most common cancer in men. An estimated 1.1 million men worldwide were diagnosed in 2012, with 345,000 cases in the European Union [1]. Estimates of public health expenditure on cancer indicate that prostate was the third contributor $(6 \%$ of the total), after colorectal and breast tumours [2]. Furthermore, United States (US) projections for the 2010-2020 period indicate a $27 \%$ increase in cancer medical costs, where the largest is the continuing care phase of prostate cancer (42\%) [3].

Currently, most of the patients diagnosed (94\%) have localized prostate cancer [4] (ie, stage T1 or T2), and the number of treatments continues to increase $[5,6]$. Despite the similar proven efficacy in terms of overall survival [7], these treatments differ substantially in their side effects pattern [8-11]. With so many different alternatives, health economics may contribute with relevant information for decision-making on treatment for localized prostate cancer [12], and there has been an increasing number of economic evaluations worldwide: comparing surgery versus radiotherapy $[13,14]$, different variations of prostatectomy [13, 15-17] or radiotherapy [13, 14, 18-21].

The National Institute for Clinical Excellence (NICE) published a global systematic review of economic evaluations for localized prostate cancer treatments in 2003 [22], before the new surgical and radiotherapy modalities appeared. Since, only two other systematic reviews have been published on economic evaluations. One, focusing on radiotherapy [23], identified 14 studies. The other one, evaluating radical prostatectomy, did not identify any complete economic evaluation meeting inclusion criteria, but instead included 11 cost comparison studies [24]. To our knowledge, there is no global systematic review that takes into account the economic evaluations of all treatments published during the last 15 years, including those comparing different therapies, such as radical prostatectomy versus radiotherapy or active surveillance. As a consequence, the efficiency of existing treatment options for localized prostate cancer is still uncertain.

Most of the economic evaluations were conducted in the US [23-26], yet differences in health systems across countries limit their results' generalizability. Although there are also important differences within European countries, they share some major principles (such as a mainly publicly funded and almost universal coverage) far away from the insurance-based US health care system. Since economic evaluations are relevant to local context, our interest was centered in those performed in Europe. The aim of this study was to assess the efficiency of treatments in patients with localized prostate cancer, by synthesizing the available evidence from European economic evaluations through systematic review.

\section{Methods}

The protocol was registered in PROSPERO (http:// www.crd.york.ac.uk/Prospero) with number CRD42015 022063. We conducted systematic searches in MEDLINE, EMBASE and NHS EED (NHS Economic Evaluation Database, CRD York) databases with a specific strategy (see online Additional file 1) from January 1st 2000 to December 31st 2015.

We looked for economic evaluations (cost minimization, cost-effectiveness, cost-utility, and cost-benefit analyses) or cost comparison studies that assessed any modality of surgery or radiotherapy treatments, regardless of the comparator/s, for patients with localized prostate cancer (T1-T2). Articles were considered when referring to any European country, and published in any European language.

Studies were excluded if they only performed cost estimations without comparing treatments (such as cost studies, cost of illness studies, or budget impact analyses); they were not primary studies (reviews, editorials or commentaries); they assessed patients with advanced prostate cancer; or they evaluated diagnosis or screening procedures, but no treatments.

Two members of the study team (JJ and VB) independently reviewed articles found in the literature search by examining them in three consecutive phases: titles, abstracts, and full text. A third reviewer (MA) resolved discrepancies. A pilot test was performed to homogenize criteria among reviewers. Finally, the reference lists of the selected articles and those of previous systematic reviews were reviewed to identify other possible studies that could be included. Coding for inclusion and exclusion criteria were defined and recorded for each stage.

Assessment of studies' quality and data extraction was performed by the consensus of two reviewers (VB and MA). Drummond's Checklist was used for quality assessment [27]. Data was extracted using a standardized, prepiloted data collection form, including participant characteristics, interventions, comparator, economic perspective, and time horizon among others. The pre-defined primary outcome to be extracted was the incremental cost per Quality-Adjusted Life-Year (QALY) gained. Other Incremental Cost-Effectiveness Ratios (ICERs) and comparative costs per treatment were considered secondary outcomes. For illustrative purposes a figure has been designed to show all estimations of accumulated cost converted into euros (considering the current 2015 exchange rates), and plotted them through the time horizon for each intervention. Patient Intervention Comparator Outcome (PICO) strategy for this review is shown in the online Additional file 2 .

\section{Results}

Literature flow in the systematic review

Figure 1 shows the Preferred Reporting Items for Systematic Reviews and Meta-Analyses (PRISMA) 


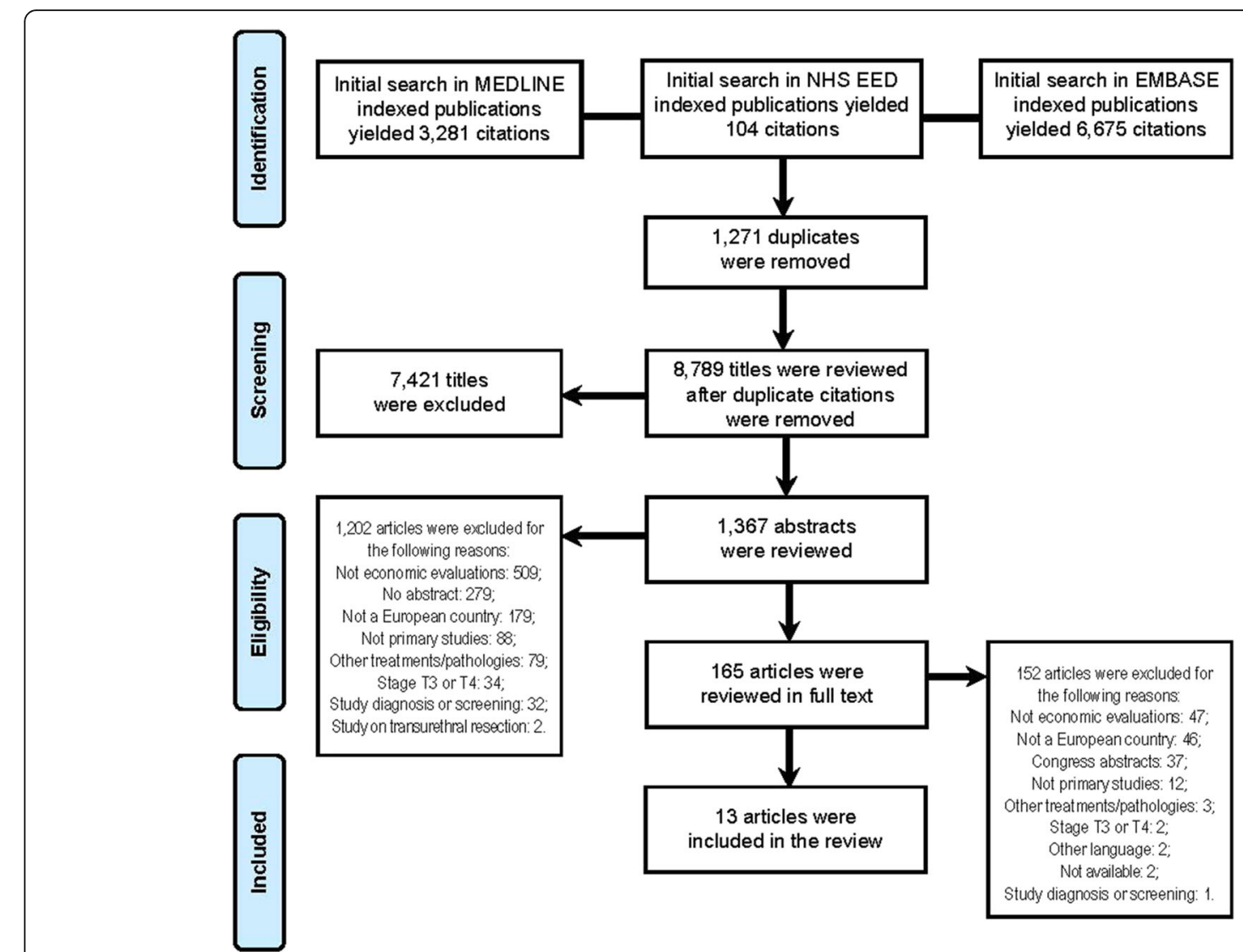

Fig. 1 Preferred Reporting Items for Systematic Reviews and Meta-Analyses (PRISMA) Flow of Literature Diagram

diagram. Once 1,271 duplicates were excluded, 8,789 titles and 1,367 abstracts were reviewed, 165 articles were fully read, and finally only 13 eligible studies were included. Overall agreement and kappa coefficients $(\mathrm{k})$ between reviewers were $79.7 \%(k=0.35)$, $92.8 \%(k=0.63)$, and $88.3 \%(k=0.53)$ in the title, abstract, and full text stages, respectively.

\section{Characteristics of economic evaluations identified in the systematic review}

Table 1 shows the characteristics of the 13 economic evaluations which met the inclusion criteria [22, 28-39]. Most were conducted in the United Kingdom (UK), Sweden, and France. All were complete economic evaluations, except two cost-comparisons [30, 34]: eight were cost-utility analyses, two cost-effectiveness analyses $[31,39]$ and one costminimization analysis [38]. Studies were classified according to the treatments they evaluated: a) in five studies [22, 28-31] interventions were compared with expectant management (watchful waiting or active surveillance); b) four studies compared robotic-assisted laparoscopic prostatectomy with other surgical techniques [32-35]; c) three studies contrasted conventional external radiotherapy with new modalities [22, 36, 37] (Intensity-Modulated Radiation Therapy-IMRT, proton therapy and brachytherapy); and d) three studies compared radical prostatectomy with radiotherapy [22, 38, 39]. Only the 2003 Hummel et al. study [22] provided data for more than one of these classification groups (a, c and d).

Most of the evaluations (nine out of 13) were conducted from a payer's perspective. Regarding the time horizon, lifetime (assuming an age limit of 100 years) was considered in five studies [22, 28, 32, 36, 37], one decade in three other studies [29, 30,33], and shorter periods for the rest (from hospital stay to 5 years). Source of cost was medical records from study cohorts, such as the Scandinavian Prostatic Cancer Group Study Number 4 (SPCG-4) [40], or national database registers of activities such as the British $\mathrm{Na}$ tional Health System (NHS) or, more rarely, only literature review (two studies) [36, 37]. Similar sources were used for effects on health. Only in seven studies the threshold to consider an alternative as costeffective was clearly stated [28, 29, 32, 33, 36, 37, 41]. It ranged from $€ 20,000$ to $€ 55,000$ per QALY gained, 


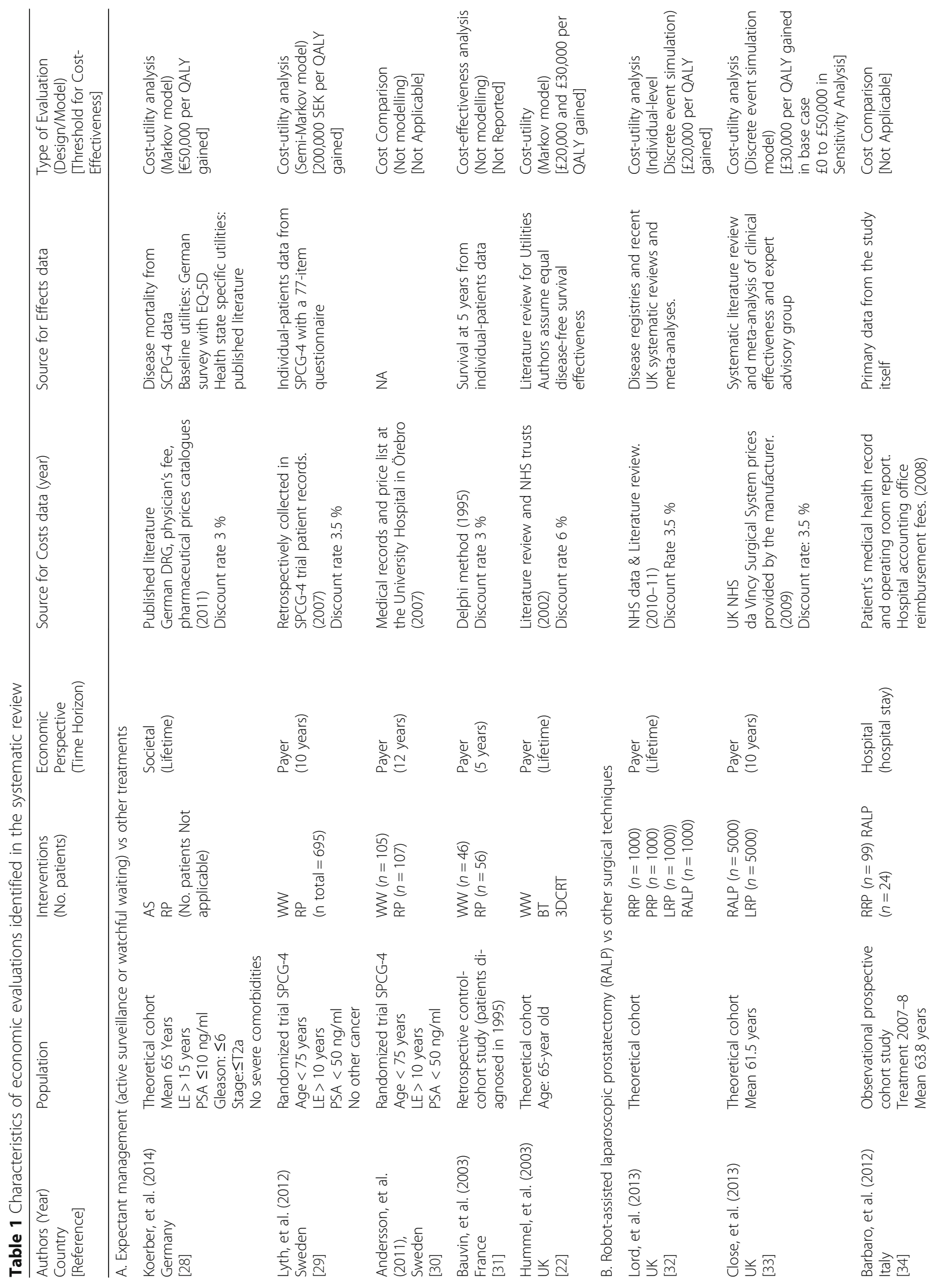




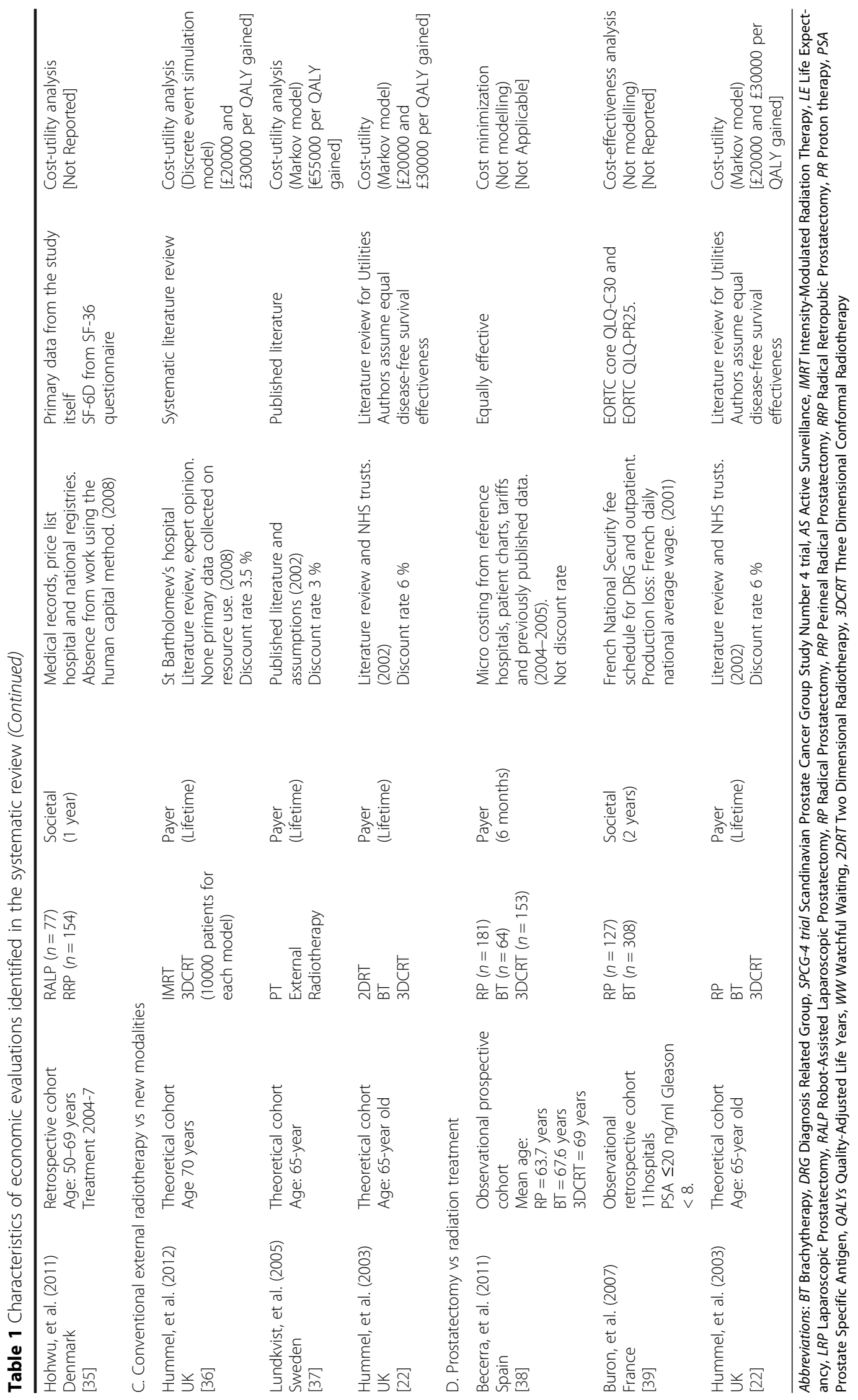


Table 2 Main findings of economic evaluations identified in the systematic review

\begin{tabular}{|c|c|c|c|c|}
\hline $\begin{array}{l}\text { Authors (Year) } \\
\text { Country } \\
\text { [Reference] }\end{array}$ & $\begin{array}{l}\text { Mean Cost } \\
\text { Mean Incremental }(\Delta) \\
\text { Cost }\end{array}$ & $\begin{array}{l}\text { Effectiveness } \\
\text { measure or } \\
\text { Incremental }(\Delta)\end{array}$ & ICER & Sensitivity Analyses Conclusions \\
\hline
\end{tabular}

A. Expectant management (active survaillance or watchful waiting) vs other treatments

\begin{tabular}{|c|c|c|c|c|}
\hline $\begin{array}{l}\text { Koerber, et al. (2014) } \\
\text { [28] }\end{array}$ & $\begin{array}{l}\text { Mean Cost: } \\
\text { RP } € 16468 ; A S € 9585 \\
\text { Mean } \Delta \text { Cost RP vs AS: } \\
€ 6883\end{array}$ & $\begin{array}{l}\text { Life expectancy: } \\
\text { RP 12.15; AS } 12.07 \\
\text { QALYS: } \\
\text { RP 7.56; AS } 7.60\end{array}$ & $\begin{array}{l}€ / \text { Life year gained } \\
\text { for RP: } 96420 \\
€ / \text { QALY gained: } \\
\text { AS resulted a } \\
\text { dominant strategy } \\
\text { over RP. }\end{array}$ & $\begin{array}{l}\text {-Probability of } \\
\text { metastases in A } \\
\text {-AS utility weigh } \\
\text {-Time horizon: } 5 \\
\text { and } 30 \text { years. } \\
\text {-Discount rate } 0 \\
\text { and } 10 \%\end{array}$ \\
\hline $\begin{array}{l}\text { Lyth, et al. (2012) } \\
\text { [29] }\end{array}$ & $\begin{array}{l}\text { Mean } \Delta \text { Cost RP vs WW: } \\
\text { S1-SEK } 40116 \\
\text { S2-SEK } 49784 \\
\text { S3-SEK } 59160 \\
\text { S4-SEK } 63834 \\
\text { S5-SEK } 70074 \\
\text { S6-SEK } 72439\end{array}$ & $\begin{array}{l}\triangle \text { QALY: } \\
\text { S1-0.57 } \\
\text { S2-0.86 } \\
\text { S3-0.25 } \\
\text { S4-0.42 } \\
\text { S5-0.08 } \\
\text { S6-0.15 }\end{array}$ & $\begin{array}{l}\text { SEK/QALY gained for } \\
\text { RP: } \\
\text { S1-70766 } \\
\text { S2-58045 } \\
\text { S3-232409 } \\
\text { S4-150274 } \\
\text { S5-858703 } \\
\text { S6-472327 }\end{array}$ & $\begin{array}{l}\text { Scenarios: } \\
\text { S1-65y Gleason } \\
\text { S2-65y Gleason } \\
\text { S3-70y Gleason } \\
\text { S4-70y Gleason } \\
\text { S5-75y Gleason } \\
\text { S6-75y Gleason }\end{array}$ \\
\hline $\begin{array}{l}\text { Andersson, et al. (2011) } \\
\text { [30] }\end{array}$ & $\begin{array}{l}\text { Mean Cost: } \\
\text { RP €24247; WW €18124 }\end{array}$ & Not Applicable & Not Applicable & Not Applicable \\
\hline $\begin{array}{l}\text { Bauvin, et al. (2003) } \\
\text { [31] }\end{array}$ & $\begin{array}{l}\text { Mean Cost: } \\
\text { RP €8533; WW €2143 }\end{array}$ & $\begin{array}{l}5 \text { year survival: } \\
\text { RP } 89 \% \text {; WW } 78 \% \\
5 \text { year relative } \\
\text { survival: } \\
\text { RP } 97 \% \text {; WW } 95 \%\end{array}$ & ICER not reported & Not reported \\
\hline $\begin{array}{l}\text { Hummel, et al. (2003) } \\
\text { [22] }\end{array}$ & $\begin{array}{l}\text { Mean Cost: } \\
\text { WW } £ 1714 \\
\text { BT £6880 } \\
\text { 3DCRT £2103 }\end{array}$ & $\begin{array}{l}\text { QALYs: } \\
\text { WW } 8.88 \\
\text { BT } 9.28 \\
\text { 3DCRT } 8.89\end{array}$ & $\begin{array}{l}\text { £/QALY gained (WW } \\
\text { as reference): } \\
-12828 \text { for BT } \\
-26766 \text { for 3DCRT }\end{array}$ & $\begin{array}{l}\text {-Incidence of } \\
\text { adverse events } \\
\text {-Utilities } \\
\text {-Age } \\
\text {-Costs }\end{array}$ \\
\hline
\end{tabular}

B. Robot-assisted laparoscopic prostatectomy (RALP) vs other surgical techniques

$\begin{array}{llll}\text { Lord, et al. (2013) } & \text { Mean Costs: } & \text { QALYs: } & \text { £/QALY gained: } \\ \text { [32] } & \text { RRP £6485; LRP £6534 } & \text { RRP 7.937; LRP 7.936 } & \text { RALP resulted a } \\ & \text { PRP £6510; RALP £6458 } & \text { PRP 7.936; RALRP } & \text { dominant strategy } \\ & & 7.943 & \text { over all other }\end{array}$

Close, et al. (2013)

[33]

\author{
Mean Costs: \\ RALP £9040; LRP £7628 \\ $\mathrm{N}^{\circ}$ Procedures/year (P/ \\ year) \\ 200 RALP £9040; LRP \\ $£ 7628$ \\ 150 RALP £9799; LRP \\ $£ 7628$ \\ 100 RALP £11312; LRP \\ $£ 7628$
}

"AS is likely to be a cost-saving treatment strategy for some patients with early stage localized prostate cancer. However, cost-effectiveness is dependent on patients' valuation of health states $[\ldots]^{\prime \prime}$

"Assuming a threshold value of 200000 SEK/QALY gained, for patients aged $\leq 70$ years the treatment is always costeffective, except at age 70 , Gleason $0-4$ and PSA $\leq 10$ $[\ldots]^{\prime \prime}$

"In this economic evaluation of RP versus WW of localized prostate cancer in a randomized study, RP was associated with $34 \%$ higher costs. [...]"

Results supported the costeffectiveness of radical prostatectomy over watchful waiting.

"[...] It is difficult therefore to draw conclusions on the relative benefits or otherwise of the newer technologies owing to the lack of substantive evidence of any quality and the lack of comparisons between the newer technologies and with standard treatments. [...]"

-Willingness-to-pay threshold

"[...] The practical usefulness of our models to guideline developers and users should also be investigated, as should the feasibility and usefulness of whole guideline modelling alongside development of a new Clinical Guidelines."

QALYs: RALP 6.52; RLP 6.44

EALY gained for RALP: -Positive margin rate after RALP

-18329 for $200 \mathrm{P} /$ year -Procedures/year -28172 for 150 P/year -Patient's lifetime -47822 for 100 P/year -Price of robotic -106839 for 50 P/year system Three-arm robot (DaVinci甲)) $£ 7009 /$ QALY for 200 P/year
"Higher costs of robotic prostatectomy may be offset by modest health gain resulting from lower risk of early harms and positive margin, provided $>150$ cases are performed each year. Considerable uncertainty persists in the absence of directly comparative randomised data." 
Table 2 Main findings of economic evaluations identified in the systematic review (Continued)

50 RALP £15859; LRP
$£ 7628$

Three-arm robot (Da

Vinci $\left.^{\oplus}\right)$ with 200 P/year:

RALP £8168; LRP £7628

Barbaro, et al. (2012) [34] RALP €20103; RRP €276

\section{Not Applicable Not Applicable}

Mean Hospital Costs:

RALP €3358; RRP €2791

Mean Total Costs:

RALP €23610; RRP €5635
Hohwu, et al. (2011)

[35]
Mean direct costs: RALP $€ 8369$

RRP $€ 3863$

Mean Indirect costs:

RALP $€ 13411$

RRP $€ 12465$
Successful treatment: $€$ /extra successful RALP $34 \%$; RRP

$27 \%$

$\triangle \mathrm{QALYS}:$

RALP 0.0103; RRP

0.0116

-64343 for direct

costs

costs
C. Conventional external radiotherapy vs new modalities

Hummel, et al. (2012) Mean total discounted [36]

costs:

IMRT/3DCRT

S1-£6173/£5184

S2-£4946/£4214

S3-£4946/£4486

S4-£5687/£7489

Lundkvist, et al.

(2005)

[37]
Total discounted

QALY:

S1-6.802/6.792

S2-7.070/7.046

S3-7.070/6.983

\$4-7.015/6.402

$\triangle$ QALY for Proton Therapy: 0.297/ patient

EALY gained for Proton Therapy:26776

IMRT:

S1-104066

S2-31162

S3-5295

S4-dominant

strategy.
IMRT/3DCRT
$\Delta$ total cost for standard case

Proton Therapy vs

External Radiotherapy:

$€ 7953$ per patient treatment for RALP

-13514 for indirect

$€ / Q A L Y$ gained for

RALP:

Not applicable

because no QALY

gained

-Life time for robot

-Procedures/year

£/QALY gained for
Scenarios:

S1-equal dose\& PSA relapse

S2-15\% difference

in late gastro intestinal toxicity

S3-3.8 y survival difference S4-6.6 y survival difference

Not reported
"Proton therapy was costeffective if appropriate risk groups were chosen. The results must be interpreted with caution, since there is a lack of data, and consequently large uncertainties in the assumptions used"

See above

$\begin{array}{ll}\text { Hummel, et al. (2003) } & \text { Mean total costs: } \\ \text { [22] } & \text { 2DRT } £ 1886 \\ & \text { BT } £ 6880 \\ & \text { 3DCRT £2103 }\end{array}$

D. Prostatectomy vs radiation treatment

$\begin{array}{ll}\text { Becerra, et al. (2011) } & \text { Mean total cost: } \\ \text { [38] } & \text { RP } € 6863.70 \\ & \text { BT } € 5453.60 \\ & 3 D C R T € 3336.10\end{array}$

QALYs:

2DRT 8.56

BT 9.28

3DCRT 8.89

Not Applicable
£/QALY gained

(2DRT as reference):

-8575 for BT

-683 for 3DCRT

Not Applicable

-Cost of 3DCRT
"Radical prostatectomy therapeutic proved to be the most expensive treatment option. [...] Most of the costs were explained by the therapeutic option, and neither comorbidity nor risk groups showed an effect of total costs independent of treatment."

"This study suggests a similar cost profile in France for BT and RP but with different $\begin{array}{ll}\text { Buron, et al. (2007) } & \text { Mean societal cost: } \\ \text { [39] } & \text { BT €8019; RP €8715 }\end{array}$
Urinary incontinence ICER not reported Not reported BT $20 \%$; RP $49 \%$

Fecal incontinence 
Table 2 Main findings of economic evaluations identified in the systematic review (Continued)

\begin{tabular}{|c|c|c|c|c|c|}
\hline & $\begin{array}{l}\text { Mean Initial treatment } \\
\text { costs: } \\
\text { BT €7159; RP €6472 } \\
\text { Mean hospital follow-up } \\
\text { costs: } \\
\text { BT €268; RP €992 } \\
\text { Mean Outpatient costs: } \\
\text { BT €482; RP €419 } \\
\text { Mean loss productivity } \\
\text { costs: } \\
\text { BT €620; RP €3678 }\end{array}$ & $\begin{array}{l}\text { BT } 9 \% \text {; RP } 2 \% \\
\text { Rectal Bleeding } \\
\text { BT } 15 \% \text {; RP } 0 \% \\
\text { Erectile Dysfunction } \\
\text { BT } 45.8 \% \text {; RP } 83.3 \%\end{array}$ & & & $\begin{array}{l}\text { health-related quality of life } \\
\text { and side effect profiles. Those } \\
\text { findings may be used to } \\
\text { tailor localized prostate can- } \\
\text { cer treatments to suit individ- } \\
\text { ual patients' needs." }\end{array}$ \\
\hline $\begin{array}{l}\text { Hummel, et al. (2003) } \\
\text { [22] }\end{array}$ & $\begin{array}{l}\text { Mean total costs: } \\
\text { RP £6359 } \\
\text { BT £6880 } \\
\text { 3DCRT £2103 }\end{array}$ & $\begin{array}{l}\text { QALYs } \\
\text { RP } 8.93 \\
\text { BT } 9.28 \\
\text { 3DCRT } 8.89\end{array}$ & $\begin{array}{l}£ / Q A L Y \text { gained (RP } \\
\text { as reference): } \\
\text {-12828 for BT } \\
\text {-Not Applicable }\end{array}$ & $\begin{array}{l}\text { - Incidence of } \\
\text { adverse events } \\
\text {-Utilities } \\
\text {-Age } \\
\text {-Costs }\end{array}$ & See above \\
\hline
\end{tabular}

Abbreviations: AS Active Surveillance, BT Brachytherapy, ICER Incremental Cost-Effectiveness Ratio, IMRT Intensity-Modulated Radiation Therapy, LRP Laparoscopic Prostatectomy, RALP Robot-Assisted Laparoscopic Prostatectomy, RP Radical Prostatectomy, PRP Perineal Radical Prostatectomy, RRP Radical Retropubic Prostatectomy, QALYs Quality-Adjusted Life Years, WW Watchful Waiting, 2DRT Two Dimensional Radiotherapy, 3DCRT Three Dimensional Conformal Radiotherapy

and four studies carried out sensitivity analysis around this threshold [22, 28, 32, 33].

\section{Main findings of economic evaluations identified in the systematic review}

Estimated total direct cost for every treatment alternative was reported in all but two of the studies (see Table 2), which only showed incremental cost difference $[29,37]$. Eight studies could provide incremental cost per QALY gained [22, 28, 29, 32, 33, 35-37], and four studies other outcomes such as life year gained [28], 5year survival [31], successful treatment [35], and treatment side effects [39].

Of the interventions evaluated, three were found to be not only cost-effective but also dominant strategies (more effective and less costly): active surveillance over radical prostatectomy from a societal perspective in Germany [28], robotic-assisted over non-robotic surgical techniques [32], and IMRT over 3-Dimensional Conformal Radiation Therapy (3DCRT) when assuming a survival improvement of 6.6 years [36]. The following six interventions were found to be cost-effective: radical prostatectomy over watchful waiting in patients aged 70 or younger [29], robotic-assisted over non-robotic laparoscopic radical prostatectomy if more than 150 procedures performed per year [33], IMRT over 3DCRT when survival improvement is $\geq 3.8$ years [36], and proton therapy [37], brachytherapy [22] and 3DCRT [22] over conventional radiotherapy. Conversely, the highest cost per QALY gained (least efficient options) were shown for radical prostatectomy versus watchful waiting in patients older than 75 [29], robotic-assisted versus non-robotic radical prostatectomy performing 50 procedures per year [33] (over $£ 100,000$ ), and for IMRT versus 3DCRT at equal doses and same survival to Prostate-Specific Antigen (PSA) progression [36] (over €100,000).
Estimations of accumulated direct costs in euros were plotted through the time horizon in Fig. 2 for each intervention. In total, the figure shows 38 estimates reported by 11 studies. The lowest costs (around €2,000) were obtained for expectant management (specifically, watchful waiting) at time horizons of 5 years and lifetime, as reported by Bauvin et al. [31] and Hummel et al. [22], respectively. The highest costs (around $€ 24,000$ ) were obtained for roboticassisted surgery during hospitalization [34] and for radical prostatectomy at 12 years [30].

\section{Quality of the economic evaluations identified in the systematic review}

The quality of the studies according to Drummond's 10item checklist is illustrated in Table 3. From the 11 economic evaluations, nine studies scored $\geq 8$ points. The item that most frequently failed was about effectiveness, appraised uncertain or negative in six studies.

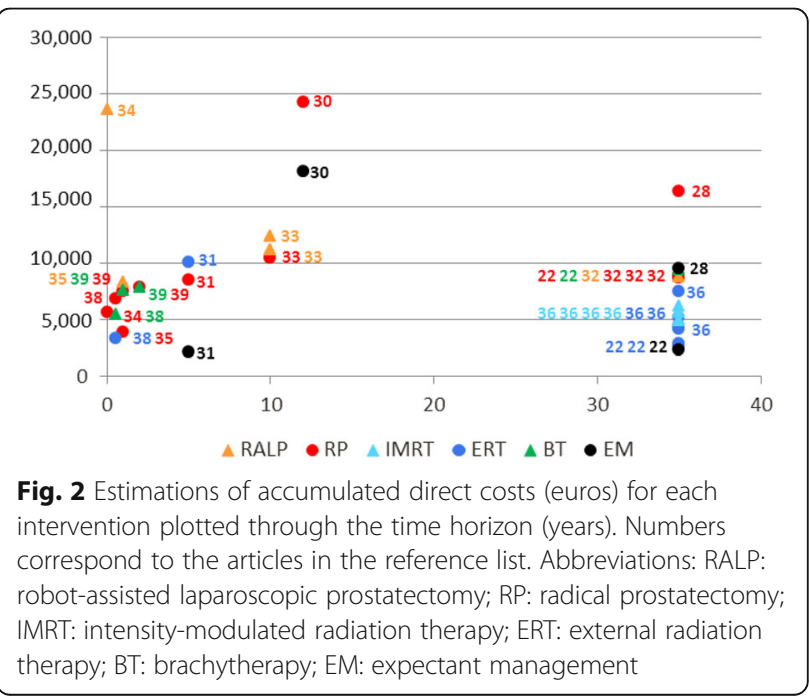


Table 3 Methodological quality assessment of economic evaluations using Drummond's 10-item checklist

\begin{tabular}{|c|c|c|c|c|c|c|c|c|c|c|c|}
\hline (Yes/no/can't tell) & $\begin{array}{l}\text { Koerber } \\
{[28]}\end{array}$ & $\begin{array}{l}\text { Lyth } \\
{[29]}\end{array}$ & $\begin{array}{l}\text { Bauvin } \\
{[31]}\end{array}$ & $\begin{array}{l}\text { Hummel } \\
\text { [22] }\end{array}$ & $\begin{array}{l}\text { Lord } \\
{[32]}\end{array}$ & $\begin{array}{l}\text { Close } \\
{[33]}\end{array}$ & $\begin{array}{l}\text { Hohwu } \\
{[35]}\end{array}$ & $\begin{array}{l}\text { Hummel } \\
{[36]}\end{array}$ & $\begin{array}{l}\text { Lundkvist } \\
{[37]}\end{array}$ & $\begin{array}{l}\text { Becerra } \\
{[38]}\end{array}$ & $\begin{array}{l}\text { Buron } \\
{[39]}\end{array}$ \\
\hline $\begin{array}{l}\text { 1. Was a well-defined question posed in } \\
\text { answerable form? }\end{array}$ & Yes & Yes & Yes & Yes & Yes & Yes & Yes & Yes & Yes & Yes & Yes \\
\hline $\begin{array}{l}\text { 2. Was a comprehensive description of the } \\
\text { competing alternatives given (i.e. can you } \\
\text { tell who did what to whom, where, and } \\
\text { how often)? }\end{array}$ & Yes & Yes & Yes & Yes & Yes & Yes & Yes & Yes & Yes & Yes & Yes \\
\hline $\begin{array}{l}\text { 3. Was the effectiveness of the programme } \\
\text { or services established? }\end{array}$ & $\begin{array}{l}\text { Can't } \\
\text { Tell }\end{array}$ & $\begin{array}{l}\text { Can't } \\
\text { Tell }\end{array}$ & Yes & No & $\begin{array}{l}\text { Can't } \\
\text { Tell }\end{array}$ & Yes & Yes & Yes & Can't Tell & No & Yes \\
\hline $\begin{array}{l}\text { 4. Were all the important and relevant costs } \\
\text { and consequences for each alternative } \\
\text { identified? }\end{array}$ & Yes & Yes & Yes & Yes & Yes & Yes & Yes & Yes & Can't Tell & Yes & Yes \\
\hline $\begin{array}{l}\text { 5. Were costs and consequences measured } \\
\text { accurately in appropriate physical units' }\end{array}$ & Yes & Yes & No & Yes & Yes & Yes & Yes & Yes & Can't Tell & Yes & Yes \\
\hline $\begin{array}{l}\text { 6. Were costs and consequences valued } \\
\text { credibly? }\end{array}$ & Yes & Yes & $\begin{array}{l}\text { Can't } \\
\text { Tell }\end{array}$ & Yes & Yes & Yes & No & Yes & Can't Tell & Yes & Yes \\
\hline $\begin{array}{l}\text { 7. Were costs and consequences adjusted } \\
\text { for differential timing? }\end{array}$ & Yes & Yes & Yes & Yes & Yes & Yes & No & Yes & Yes & No & No \\
\hline $\begin{array}{l}\text { 8. Was an incremental analysis of costs and } \\
\text { consequences of alternatives performed? }\end{array}$ & Yes & Yes & No & Yes & Yes & Yes & Yes & Yes & Yes & Yes & Yes \\
\hline $\begin{array}{l}\text { 9. Was allowance made for uncertainty in } \\
\text { the estimates of costs and consequences? }\end{array}$ & Yes & Yes & No & Yes & Yes & Yes & Yes & Yes & No & Yes & Yes \\
\hline $\begin{array}{l}\text { 10. Did the presentation and discussion of } \\
\text { study results include all issues of } \\
\text { concern to users? }\end{array}$ & Yes & Yes & $\begin{array}{l}\text { Can't } \\
\text { Tell }\end{array}$ & Yes & Yes & Yes & Yes & Yes & Can't Tell & Yes & Yes \\
\hline Score (Total) & 9 & 9 & 5 & 9 & 9 & 10 & 8 & 10 & 4 & 8 & 9 \\
\hline
\end{tabular}

Number between square brackets corresponds to reference list position

\section{Discussion}

Our systematic literature review identified 13 European studies, published 2000-2015, which conducted either economic evaluations or cost comparisons (11 and two, respectively) of any modality of surgical or radiotherapy treatments for localized prostate cancer patients. These studies varied widely in compared alternatives, costing methodologies, and time horizon. Estimations of incremental cost per QALY gained were provided by eight studies. Depending on the scenario and the comparator considered, three interventions were qualified as dominant (active surveillance [28], robotic-assisted surgery [32], and IMRT [36]), and six as cost-effective (radical prostatectomy [29], robotic-assisted surgery [33], IMRT [36], proton therapy [37], brachytherapy [22] and 3DCRT [22]).

\section{Expectant management (active surveillance or watchful waiting) vs other treatments}

Two cost-utility analyses comparing radical prostatectomy with expectant management show contradictory results: Koerber et al. [28] found that active surveillance was the dominant alternative (more QALYs at less cost), while Lyth et al. [29] showed that radical prostatectomy was more cost-effective than watchful waiting. However, the gain in QALYs in favor of active surveillance was extremely small
(0.013) [28], and moderate-to-small in favor of radical prostatectomy $(0.57-0.86)$ [29]. On the other hand, differences in the comparator used in both studies (active surveillance [28] and watchful waiting [29]) could also partly explain this disparity. No immediate treatment was performed in watchful waiting patients [29], while active surveillance involved [28] monitoring with PSA, digital rectal examination, and biopsy. Consistent with results reported by Lyth et al. [29], the cost-effectiveness study by Bauvin et al. [31] showed that radical prostatectomy is more effective than watchful waiting. Unfortunately, although the economic evaluation of Hummel et al. [22] also evaluated radical prostatectomy, they did not report its comparison with watchful waiting.

\section{Robot-assisted laparoscopic prostatectomy (RALP) vs other surgical techniques}

The previous systematic review of economic evaluations comparing robotic-assisted vs non-robotic laparoscopic surgery [24] proved to be insufficient for decision making, leading the authors to build a de novo economic evaluation [33], which has been now included in our review. Two of the three cost-utility studies that we identified consistently support the cost-effectiveness of robotic-assisted surgery $[32,33]$. Lord et al. [32] showed that robotic-assisted technique is the dominant alternative among surgery, while 
Close et al. [33] estimated a cost of $£ 18,329$ per QALY gained. Hohwu et al. [35] found no QALY gain for roboticassisted surgery, but the authors underlined the uncertainty of their QALY estimates due to a high degree of missing data. Again, disparity among these economic evaluations is mainly due to contradictory results on effectiveness, which were based on extremely small QALY gains for the roboticassisted technique: 0.007 reported by Lord et al. [32], and 0.08 by Close et al. [33] In fact, current guidelines of the European Association of Urology [5, 6] consider all approaches (i.e., open, laparoscopic, and robotic) as acceptable for patients who are surgical candidates, because no single modality has shown a clear superiority in terms of functional or oncological results. On the other hand, it is important to highlight that the recommendation of the NICE Clinical Guideline [42] to provide robots in centers with an expected performance of at least 150 robotic-assisted operations per year, is only based on the economic evaluation published by Close et al. [33] It would be advisable to confirm this recommendation with future specific studies to help decision makers.

\section{Conventional external radiotherapy vs new modalities}

The systematic review of cost-effectiveness analysis by Amin et al. [23], comparing different radiation treatments, identified 14 studies (most from the United States, and only two from Europe [22, 36]). Although evidence suggested that brachytherapy and IMRT were more costeffective than external beam radiotherapy, the authors highlighted the uncertainties and variation among studies [23]. We only identified three European economic evaluations comparing radiation therapies, each focusing on a different new modality (IMRT [36], proton therapy [37], and brachytherapy [22]). The three showed to be more cost-effective than conventional radiotherapy. However, each of these findings came from only one study, so further research is needed to confirm them. Once again, it is important to point out that the magnitude of the QALY gains is small for scenarios evaluating IMRT (0.01-0.613) [36] or proton therapy (0.297) [37], and moderate-tosmall in favor of brachytherapy (0.72) [22]. The European Association of Urology guidelines (5) recommend IMRT for definitive treatment with external radiotherapy, and brachytherapy for patients fulfilling specific criteria (low risk, prostate volume below $50 \mathrm{~mL}$, no urinary obstruction, and no previous transurethral resection).

\section{Prostatectomy vs radiation treatment}

Of the three studies comparing prostatectomy with radiation treatment, only Hummel et al. [22] published a cost-utility analysis showing that brachytherapy was more cost-effective than surgery, with an incremental cost of $€ 2,021-2,760$ per QALY gained. Buron et al. [39] did not calculate ICERs but showed similar societal costs between radical prostatectomy and brachytherapy, though different treatment side effects: radical prostatectomy caused higher rates of urinary incontinence and erectile dysfunction, while brachytherapy presented irritative urinary and bowel symptoms more frequently. These results are consistent with the well-known side effect profiles of these treatments [8-11]. The costminimization published by Becerra et al. [38] assumed equal effectiveness in terms of survival, but did not take into account other relevant outcomes such as relapses and treatment side effects. Thus, evidence supporting the cost-effectiveness of brachytherapy over open radical prostatectomy originates from one single study [22] showing a small QALY gain (0.35), and there are no economic evaluations comparing brachytherapy with robotic-assisted surgery.

\section{Accumulated direct costs per treatment}

As shown in Fig. 2, the cost-comparison study performed in Sweden reported the highest estimation of costs for radical prostatectomy and watchful waiting $(€ 24,247$ and $€ 18,124)$ [30]; also, the cost-comparison study published by Barbaro et al. [34] showed an extreme perioperative cost in an Italian hospital for robotic surgery $(€ 23,610)$. The high cost estimated in these two empirical cost-comparison studies [30,34] (based on the observation of health care activities in real cohorts) could indicate underestimation of real costs when they are based on models from theoretical cohorts. Furthermore, the surprisingly low accumulated costs estimated in most studies with theoretical cohorts and lifetime horizon $[22,32,36]$, similar or even lower than those reported for studies with a shorter time horizon [31, 33], also suggest an underestimation of real costs in these studies.

\section{Cost and effectiveness components}

Economic evaluations have two components. Regarding the cost component, it is important to highlight the similarities of the new treatment modalities compared with the traditional techniques, such as robotic versus non-robotic surgery [33] and IMRT versus external beam radiotherapy [36], when provided under rational conditions. Besides watchful waiting, the cheapest, all other treatments seem to be quite similar: most have an equivalent total cost below $€ 17,000$. The European estimates of accumulated direct healthcare costs identified are much lower than those reported in US. For instance, Cooperberg et al. [13] considering lifetime, and Hayes et al. with a 10 year horizon [14] reported costs figures of: $\$ 20,000-38,000$ in radical prostatectomy; around $\$ 33,000$ in 3DCRT; $\$ 38,000-54,000$ in IMRT; or $\$ 25,000-44,000$ in brachytherapy. Different health systems and cost structures between US and Europe may explain these variances. 
Effectiveness is the most relevant component. However, the aforementioned disparities among studies in the identification of the most effective treatment may reflect the misinterpretation of such small QALY gains showed by the majority of them. For example, the gain of 0.013 QALYs [28] was much too small to consider active surveillance the dominant strategy over radical prostatectomy; or the gain of 0.007 QALYs [32] to consider robotic-assisted the dominant strategy over non-robotic techniques. Even the clinical relevance of the highest QALY gains identified in this review (0.57-0.86 for radical prostatectomy vs watchful waiting [29], and 0.72 for brachytherapy vs conventional radiotherapy [22]) may be questionable to be interpreted as relevant differences on effectiveness. Which is the reasonable cut-off for considering one intervention more effective than its alternative? Could gains lower than one QALY through 10 years or lifetime be considered clinically significant?

Results from US economic evaluations [13, 14] also showed no relevant differences in QALY gains for lifetime across treatments: ranging $0.5-1$ or $0.7-0.8$ for patients at low and intermediate risk, respectively, when comparing surgical and radiation therapies [13]; 0.9, 0.9, and 1.1 when comparing brachytherapy, IMRT and surgery with watchful waiting [14]. The clinical relevance of less than 1 year benefits between alternatives (in time horizons $>10$ years of life) is questionable, and common sense prevents from interpreting them as differences in effectiveness.

An important issue related to the generalizability of study findings is the cost-effectiveness threshold, which represents society's willingness-to-pay for an additional unit of benefit [26]. Studies from UK showed a very consistent pattern regarding this threshold: they considered NICE's thresholds of $£ 20,000-£ 30,000$ per QALY gained [22, 32, 33, 41]. Sweden studies showed a wider range for this threshold, from 200,000 SEK $(€ 21,000)$ [29] to $€ 55,000$ per QALY gained [37]. The latter was very similar to the threshold applied in the German study ( $€ 50,000$ per QALY gained) [28]. None of them was far from the US threshold's commonly accepted standard of $\$ 50,000$ per QALY gained.

\section{Limitations of the systematic review}

There are several limitations that may affect our review findings. First, we cannot be sure that no relevant study is missing from this systematic review. However, in order to find as many relevant studies as possible, we have performed the search in PubMed and EMBASE, the most comprehensive databases in health sciences, as recommended [43], as well as in a specific database for economic evaluations. In addition, we designed a very sensitive search strategy (yielding the 8,789 titles revised) and we performed an additional manual reference search. Second, no quantitative synthesis of the results by meta-analysis was planned due to the well-known high heterogeneity among health economic evaluations. Furthermore, considering the scarce number of studies comparing the same interventions, obtaining a pooled estimator would make no sense. Third, internal validity of the synthesis provided by a systematic review depends on the quality of primary studies. In our systematic review, quality could be considered good except for effectiveness, which failed in almost half of the studies. It is necessary to take into account that recruitment for randomized trials presented considerable difficulties in these patients $[44,45]$, and the only available trial, the SPCG-4 [40]-which was used in several of these economic evaluations, was conducted at the beginning of PSA era. Fourth, studies with a cost-comparison design were included despite not being economic evaluations. However, the information they provided clearly contributed to the amount and robustness of evidence on costs. Finally, Fig. 2 shows reported direct healthcare costs without transforming them into a single year to avoid manipulation. We only converted currency into euros, using 2015 exchange rates, to facilitate comparisons.

\section{Conclusions}

To our knowledge, this is the first systematic literature review of the European economic evaluations of all main primary treatments for localized prostate cancer published during the last 15 years. The 13 studies identified (five comparing interventions with expectant management, four contrasting robotic with non-robotic assisted surgery, three assessing new modalities of radiotherapy, and three comparing radical prostatectomy with brachytherapy) showed that currently relevant treatment alternatives for localized prostate cancer are scarcely assessed in economic evaluations in the European countries. Furthermore, differences between cost-comparison and cost-effectiveness studies suggest underestimation of costs in studies based on models from theoretical cohorts.

In conclusion, very limited evidence supports the costeffectiveness of radical prostatectomy versus watchful waiting, and that of brachytherapy versus radical prostatectomy. Regarding the evaluation of new treatment modalities, also limited evidence supports the cost-effectiveness of roboticassisted laparoscopic radical prostatectomy versus nonrobotic procedures, and that of brachytherapy, IMRT and proton therapy versus traditional external radiotherapy. Relevant disparities were detected among studies, mainly based on effectiveness. These apparently contradictory results may be reflecting the difficulty of interpreting small differences between treatments regarding QALY gains. Moreover, despite an acceptable methodological quality in most aspects of the studies included, the effectiveness 
uncertainty could jeopardize the internal validity of their results.

\section{Additional files}

Additional file 1: MEDLINE, EMBASE and NHS EED (NHS Economic Evaluation Database, CRD York) specific search strategies. (DOC 74 kb)

Additional file 2: Patient Intervention Comparator Outcome (PICO) strategy. (DOC $33 \mathrm{~kb}$ )

\section{Abbreviations}

2DRT: Two Dimensional Radiotherapy; 3DCRT: Three Dimensional Conformal Radiation Therapy; AS: Active Surveillance; BT: Brachytherapy; DRG: Diagnosis Related Group; ERT: External Radiation Therapy; EM: Expectant Management; ICERs: Incremental Cost-Effectiveness Ratios; IMRT: Intensity-Modulated Radiation Therapy; LE: Life Expectancy; LRP: Laparoscopic Prostatectomy; NHS: British National Health System; NHS EED: NHS Economic Evaluation Database; NICE: National Institute for Clinical Excellence; PICO: Patient Intervention Comparator Outcome; PRISMA: Preferred Reporting Items for Systematic Reviews and Meta-Analyses; PRP: Perineal Radical Prostatectomy; PSA: Prostate-Specific Antigen; QALY: Quality-Adjusted Life-Year; RALP: RobotAssisted Laparoscopic Prostatectomy; RP: Radical Prostatectomy; RRP: Radical Retropubic Prostatectomy; SPCG-4: Scandinavian Prostatic Cancer Group Study Number 4; UK: United Kingdom; US: United States; WW: Watchful Waiting

\section{Acknowledgements}

We would like to thank Aurea Martin for her writing assistance, proofreading, manuscript editing and the submission preparation process.

\section{Funding}

Financial support for this study was provided by Instituto de Salud Carlos III FEDER: Fondo Europeo de Desarrollo Regional (FIS PI08/90090 and PI13/ 00412); Agència d'Informació, Avaluació i Qualitat en Salut (AIAQS), 436/05/ 2008; Ministerio de Ciencia e Innovación (PTAT2011-04891); and DIUE of Generalitat de Catalunya (2014 SGR 748). The funding agreements ensure the authors' independence in designing the study, interpreting the data, and writing and publishing the report.

\section{Availability of data and materials}

All data generated or analysed during this study are included in the tables of this published article. There has been no meta-analysis performed, therefore no extra raw data has been produced.

\section{Authors' contributions}

VB and MF designed the study. VB, MA and JJ performed the literature search, screened, and selected and data-extracted studies. VB, MA and OG prepared the draft manuscript. LC and AP assisted in the screening, selection and data extraction of the studies. FC, JA and YP assisted in preparing the draft manuscript. All authors critically revised the draft manuscript and approved the final version.

\section{Authors' information}

Participants in the Multicentric Spanish Group of Clinically Localized Prostate Cancer: Jordi Alonso, Montse Ferrer, Olatz Garín, Yolanda Pardo, Angels Pont (IMIM-Institut de Recerca Hospital del Mar); Ana Boladeras, Ferran Ferrer, Ferran Guedea, Evelyn Martínez, Joan Pera, Montse Ventura (Institut Català d'Oncologia); Xavier Bonet, Manel Castells, José Francisco Suárez (Hospital Universitari de Bellvitge); Javier Ponce de León, Humberto Villavicencio (Fundación Puigvert); Jordi Craven-Bratle, Gemma Sancho (Hospital de la Santa Creu i Sant Pau); Adriana Ayala, Belen de Paula, Pablo Fernández (Instituto Oncológico de Guipúzcoa); Ismael Herruzo (Hospital Regional Carlos Haya); Helena Hernández, Víctor Muñoz (Hospital Meixoeiro-Complejo CHUVI); Asunción Hervas, Alfredo Ramos (Hospital Ramon y Cajal); Víctor Macias (Hospital Clínico Universitario de Salamanca); Josep Solé, Marta Bonet (Institut Oncologic del Valles-IOV); Alfonso Mariño (Centro Oncológico de Galicia); María José Ortiz (Hospital Virgen del Rocío); Pedro J. Prada (Hospital Universitario Central de Asturias).

\section{Competing interests}

None of the funding organizations had any role in the design or conduction of the study, in the data collection, management or interpretation, nor in the manuscript writing, reviewing or approval. All authors declare that they have no competing interests.

\section{Consent for publication}

Not applicable.

\section{Ethics approval and consent to participate}

Ethics issues have been considered according to the design of the primary studies included in this systematic review: economic evaluations based on theoretical cohorts do not require ethics approval; for studies with patients, we checked if they all stated they had been approved by their Ethics Committee; all studies stated this except for the study published by Barbaro et al. in 2012.

\section{Author details}

${ }^{1}$ Health Services Research Group, IMIM (Hospital del Mar Medical Research Institute), Barcelona, Spain. ${ }^{2}$ Universitat Pompeu Fabra, Barcelona, Spain. ${ }^{3}$ CIBER en Epidemiología y Salud Pública, CIBERESP, Madrid, Spain. ${ }^{4}$ Unidad de Investigación Médica en Enfermedades Renales, Hospital de Especialidades, IMSS, Guadalajara, México. ${ }^{5}$ Epidemiology and Evaluation Department, IMIM (Hospital del Mar Medical Research Institute), Barcelona, Spain. ${ }^{6}$ Health Services Research on Chronic Patients Network (Red de Investigación en Servicios de Salud en Enfermedades Crónicas [REDISSEC]), Barcelona, Spain. ${ }^{7}$ Universitat Autònoma de Barcelona, Bellaterra, Spain.

Received: 6 February 2016 Accepted: 22 September 2016

Published online: 03 October 2016

\section{References}

1. Bray F, Ren JS, Masuyer E, Ferlay J. Estimates of global cancer prevalence for 27 sites in the adult population in 2008. Int J Cancer. 2013;132:1133-45.

2. Blakely T, Atkinson J, Kvizhinadze G, Wilson N, Davies A, Clarke P. Patterns of cancer care costs in a country with detailed individual data. Med Care. 2015:53:302-9.

3. Mariotto $A B$, Yabroff KR, Shao Y, Feuer EJ, Brown ML. Projections of the cost of cancer care in the United States: 2010-2020. J Natl Cancer Inst. 2011;103:117-28.

4. Shao YH, Demissie K, Shih W, Mehta AR, Stein MN, Roberts CB, et al. Contemporary risk profile of prostate cancer in the United States. J Natl Cancer Inst. 2009;101:1280-3.

5. Mohler JL, Armstrong AJ, Bahnson RR, Boston B, Busby JE, D'Amico AV, et al. Prostate cancer, Version 3.2012: featured updates to the NCCN guidelines. J Natl Compr Canc Netw. 2012;10:1081-7.

6. Mottet N, Bellmunt J, Briers E, van den Bergh RCN, Bolla M, van Casteren NJ, et al. Guidelines on Prostate Cancer-UPDATE MARCH 2015. European Association of Urology (EUA); 2015. https://uroweb.org/wp-content/ uploads/09-Prostate-Cancer_LR.pdf.

7. Wilt TJ, MacDonald R, Rutks I, Shamliyan TA, Taylor BC, Kane RL. Systematic review: comparative effectiveness and harms of treatments for clinically localized prostate cancer. Ann Intern Med. 2008;148:435-48.

8. Sanda MG, Dunn RL, Michalski J, Sandler HM, Northouse L, Hembroff L, et al. Quality of life and satisfaction with outcome among prostate-cancer survivors. N Engl J Med. 2008;358:1250-61.

9. Litwin MS, Gore JL, Kwan L, Brandeis JM, Lee SP, Withers HR, et al. Quality of life after surgery, external beam irradiation, or brachytherapy for early-stage prostate cancer. Cancer. 2007;109:2239-47.

10. Pardo Y, Guedea F, Aguilo F, Fernandez P, Macias V, Marino A, et al. Qualityof-life impact of primary treatments for localized prostate cancer in patients without hormonal treatment. J Clin Oncol. 2010;28:4687-96.

11. Chen RC, Clark JA, Talcott JA. Individualizing quality-of-life outcomes reporting: how localized prostate cancer treatments affect patients with different levels of baseline urinary, bowel, and sexual function. J Clin Oncol. 2009;27:3916-22.

12. Kommu SS, Eden CG, Luscombe CJ, Golash A, Persad RA. Initial treatment costs of organ-confined prostate cancer: a general perspective. BJU Int. 2011;107:1-3.

13. Cooperberg MR, Ramakrishna NR, Duff SB, Hughes KE, Sadownik S, Smith JA, et al. Primary treatments for clinically localised prostate cancer: a comprehensive lifetime cost-utility analysis. BJU Int. 2013;111:437-50. 
14. Hayes JH, Ollendorf DA, Pearson SD, Barry MJ, Kantoff PW, Lee PA, et al. Observation versus initial treatment for men with localized, low-risk prostate cancer: a cost-effectiveness analysis. Ann Intern Med. 2013;158:853-60.

15. Bolenz C, Gupta A, Hotze T, Ho R, Cadeddu JA, Roehrborn CG, et al. Cost comparison of robotic, laparoscopic, and open radical prostatectomy for prostate cancer. Eur Urol. 2010;57:453-8.

16. Anderson JK, Murdock A, Cadeddu JA, Lotan Y. Cost comparison of laparoscopic versus radical retropubic prostatectomy. Urology. 2005;66:557-60.

17. Mouraviev V, Nosnik I, Sun L, Robertson CN, Walther P, Albala D, et al. Financial comparative analysis of minimally invasive surgery to open surgery for localized prostate cancer: a single-institution experience. Urology. 2007;69:311-4.

18. Hodges JC, Lotan Y, Boike TP, Benton R, Barrier A, Timmerman RD. Costeffectiveness analysis of SBRT versus IMRT: an emerging initial radiation treatment option for organ-confined prostate cancer. Am J Manag Care. 2012;18:e186-93.

19. Konski A, Watkins-Bruner D, Feigenberg S, Hanlon A, Kulkarni S, Beck JR, et al. Using decision analysis to determine the cost-effectiveness of intensity-modulated radiation therapy in the treatment of intermediate risk prostate cancer. Int J Radiat Oncol Biol Phys. 2006;66:408-15.

20. Poon I, Pintilie M, Potvin M, McGowan T. The changing costs of radiation treatment for early prostate cancer in Ontario: a comparison between conventional and conformal external beam radiotherapy. Can J Urol. 2004;11:2125-32

21. Norderhaug I, Dahl O, Hoisaeter PA, Heikkila R, Klepp O, Olsen DR, et al. Brachytherapy for prostate cancer: a systematic review of clinical and cost effectiveness. Eur Urol. 2003:44:40-6.

22. Hummel S, Paisley S, Morgan A, Currie E, Brewer N. Clinical and costeffectiveness of new and emerging technologies for early localised prostate cancer: a systematic review. Health Technol Assess. 2003;7:iii, ix-iii, 157.

23. Amin NP, Sher DJ, Konski AA. Systematic review of the cost effectiveness of radiation therapy for prostate cancer from 2003 to 2013. Appl Health Econ Health Policy. 2014;12:391-408.

24. Ramsay C, Pickard R, Robertson C, Close A, Vale L, Armstrong N, et al. Systematic review and economic modelling of the relative clinical benefit and cost-effectiveness of laparoscopic surgery and robotic surgery for removal of the prostate in men with localised prostate cancer. Health Technol Assess. 2012;16:1-313.

25. Gianino MM, Galzerano M, Minniti D, Di NC, Martin B, Davini O, et al. A comparative costs analysis of brachytherapy and radical retropubic prostatectomy therapies for clinically localized prostate cancer. Int J Technol Assess Health Care. 2009;25:411-4.

26. Oppong R, Jowett S, Roberts TE. Economic Evaluation alongside Multinational Studies: A Systematic Review of Empirical Studies. PLoS One. 2015;10:e0131949.

27. Drummond MF. Methods for the economic evaluation of health care programmes. 3rd ed. Oxford: Oxford University Press; 2005

28. Koerber F, Waidelich R, Stollenwerk B, Rogowski W. The cost-utility of open prostatectomy compared with active surveillance in early localised prostate cancer. BMC Health Serv Res. 2014;14:163.

29. Lyth J, Andersson SO, Andren O, Johansson JE, Carlsson P, Shahsavar N. A decision support model for cost-effectiveness of radical prostatectomy in localized prostate cancer. Scand J Urol Nephrol. 2012;46:19-25.

30. Andersson SO, Andren O, Lyth J, Stark JR, Henriksson M, Adami HO, et al. Managing localized prostate cancer by radical prostatectomy or watchful waiting: Cost analysis of a randomized trial (SPCG-4). Scand J Urol Nephrol. 2011:45:177-83

31. Bauvin E, Molinier L, Dervaux B, Soulie M, Latorzeff I, Bachaud JM, et al. Cost and efficacy of treatment strategies in localized prostatic cancer: feasibility study in the general population. Prog Urol. 2003;13:618-23.

32. Lord J, Willis S, Eatock J, Tappenden P, Trapero-Bertran M, Miners A, et al. Economic modelling of diagnostic and treatment pathways in National Institute for Health and Care Excellence clinical guidelines: the Modelling Algorithm Pathways in Guidelines (MAPGuide) project. Health Technol Assess. 2013;17:v-192

33. Close A, Robertson C, Rushton S, Shirley M, Vale L, Ramsay C, et al. Comparative cost-effectiveness of robot-assisted and standard laparoscopic prostatectomy as alternatives to open radical prostatectomy for treatment of men with localised prostate cancer: a health technology assessment from the perspective of the UK National Health Service. Eur Urol. 2013;64:361-9.
34. Barbaro S, Paudice A, Scipioni S, Martin B, Charrier L, Bert F, et al. Robotassisted radical prostatectomy: a minihealth technology assessment in a teaching hospital. HealthMED. 2012;6:724-30.

35. Hohwu L, Borre M, Ehlers L, Venborg PK. A short-term cost-effectiveness study comparing robot-assisted laparoscopic and open retropubic radical prostatectomy. J Med Econ. 2011;14:403-9.

36. Hummel SR, Stevenson MD, Simpson EL, Staffurth J. A model of the costeffectiveness of intensity-modulated radiotherapy in comparison with threedimensional conformal radiotherapy for the treatment of localised prostate cancer. Clin Oncol (R Coll Radiol). 2012;24:e159-67.

37. Lundkvist J, Ekman M, Ericsson SR, Jonsson B, Glimelius B. Proton therapy of cancer: potential clinical advantages and cost-effectiveness. Acta Oncol. 2005:44:850-61.

38. Becerra Bachino V, Cots F, Guedea F, Pera J, Boladeras A, Aguilo F, et al. Cost comparison of three treatments for localized prostate cancer in Spain: radical prostatectomy, prostate brachytherapy and external 3D conformal radiotherapy. Gac Sanit. 2011:25:35-43.

39. Buron C, Le VB, Cosset JM, Pommier P, Peiffert D, Delannes M, et al. Brachytherapy versus prostatectomy in localized prostate cancer: results of a French multicenter prospective medico-economic study. Int J Radiat Oncol Biol Phys. 2007;67:812-22.

40. Holmberg L, Bill-Axelson A, Helgesen F, Salo JO, Folmerz P, Haggman M, et al. A randomized trial comparing radical prostatectomy with watchful waiting in early prostate cancer. N Engl J Med. 2002;347:781-9.

41. Hummel S, Simpson EL, Hemingway P, Stevenson MD, Rees A. Intensitymodulated radiotherapy for the treatment of prostate cancer: a systematic review and economic evaluation. Health Technol Assess. 2010;14:1-iv.

42. National Institute for Health and Care Excellence (NICE). Prostate cancer: diagnosis and management. Clinical guideline. 2014.

43. Mathes T, Walgenbach M, Antoine SL, Pieper D, Eikermann M. Methods for systematic reviews of health economic evaluations: a systematic review, comparison, and synthesis of method literature. Med Decis Making. 2014:34:826-40

44. Crook JM, Gomez-Iturriaga A, Wallace K, Ma C, Fung S, Alibhai S, et al. Comparison of health-related quality of life 5 years after SPIRIT: Surgical Prostatectomy Versus Interstitial Radiation Intervention Trial. J Clin Oncol. 2011:29:362-8.

45. Wilt TJ. Can randomized treatment trials in early stage prostate cancer be completed? Clin Oncol (R Coll Radiol). 1998;10:141-3.

\section{Submit your next manuscript to BioMed Central and we will help you at every step:}

- We accept pre-submission inquiries

- Our selector tool helps you to find the most relevant journal

- We provide round the clock customer support

- Convenient online submission

- Thorough peer review

- Inclusion in PubMed and all major indexing services

- Maximum visibility for your research

Submit your manuscript at www.biomedcentral.com/submit
) Biomed Central 